\title{
Sustainability and fairness still missing in the Greek Social Insurance System
}

\author{
Nicos Christodoulakis ${ }^{1}$
}

\begin{abstract}
Despite deep cuts in pensions implemented by the recent Law 4378/2016, the Social Insurance System in Greece is still characterized by a multitude of problems - financial, social and organizational. These make it counterproductive in improving intra-generational inequality and inter-generational fairness, while its bureaucratic complexity makes the planning and implementation of reforms a difficult task. The aim of the paper is first to describe the long-term adverse dynamics and, second, to suggest a road map of changes that ensure a fairer treatment among the various categories of pensioners as well as between them and current generation employees. Such a policy should at the same time cut privileged pensions and increase the incentives for work, thus enhancing economic growth and relieving the financial burden of the system.
\end{abstract}

Keywords: Social Security, Public Pensions, Retirement, Fiscal deficits.

JEL code: H55, J33, H60

Acknowledgement: With the usual disclaimer, the authors acknowledges useful comments during various seminars held in Athens in 2016, Thessaloniki in 2017 and the Delphi Forum in March 2018. Suggestions by two anonymous referees helped to improve an earlier version of the paper. Views expressed herein are solely those of the author without implicating any of the organizations with which he is associated.

\section{Revised version: August 2018}

\footnotetext{
${ }^{1}$ Athens University of Economics \& Business (AUEB), and Hellenic Observatory LSE. 76, Patission Street, Athens 10434.nchris@aueb.gr
} 


\section{Introduction}

The Social Insurance System (SIS) in Greece is characterized by a multitude of problems - financial, social and organizational - that in the past have made it unsustainable in fiscal terms and counterproductive in improving generational fairness. On the other hand, its bureaucratic complexity makes planning and implementation of reforms a difficult task, while the short period that is typically served by political personnel in the competent ministries makes piecemeal adjustments rather than major restructuring to be more likely. The aim of the paper is first to describe the unsustainable dynamics and, second, to suggest guiding lines of feasible reforms that can improve the fundamentals of the system in the medium run.

The most alarming feature in a SIS is the lack of financial sustainability that is felt as the gap between aggregate pension expenditure paid to the current generation of pensioners and the amount of available resources widens beyond the capacity of public finances. Resources may be accumulated either in the form of insurance contributions during the working age of current pensioners or disbursed through the contributions of present time employees. If exclusively based on the former type, the system is said to be 'fully-funded' and a SIS I sustainable if the cost of pensions equals the present value working-time contributions to the social insurance funds, including the returns on investments. If the latter type finances pensions, the system is called 'Pay-As-You-Go' (PAYG) that prevails in most European and OECD countries. Its political and social attraction is that each generation of pensioners is likely to benefit more than the case of the financing being based solely on their own contributions. As famously derived by Samuelson (1954), the reason is that current generation contributions versus latter generation's ones are augmented by the rate of growth in per capita incomes plus the rate of increase of working population,

However, the premises of the social contract implied by a PAYG system are shattered if ageing dynamics are such that the share of current labour force in total population is shrinking and/or the economy enters a prolonged slump and unemployment rises. In such cases, contributions may not be sufficient to finance unfunded and generous pensions agreed under more optimistic assumptions in the past. The emerging dilemma between cutting pensions of the older or raising contributions by the younger citizens leads to generational conflicts that 
undermines social cohesion. Similar incentives for conflict are generated if the aggregate deficit in pension expenditure is financed by issuing public debt as this implies that taxes are likely to rise and borne by the current generation to repay the state's obligations to the elderly. Given the pessimistic population forecasts in Europe, it's no wonder that pension reforms are the thorniest issue of the public policy agenda in the European Union. In fact, as argued by Campanella (2016), the growing imbalances in the SIS finances pose a serious threat to the future of most members of the European Union. The situation is even more aggravated in Greece, as on top of population ageing the country suffers from a long recession and unemployment that has driven the ratio of employees to pensioners to historically low levels. Hence, a series of reforms to respond to the adverse developments is inevitable at a national level, and with a sense of urgency.

The Greek pension system is described as an open Pay-As-You-Go system with defined benefits, in the sense that pension entitlements are predetermined by a number of parameters that depend on the political circumstances prevailing upon each person's retirement, only loosely linked to the individual contributions paid during working time. This makes financing to be hostage to the health of public purse and, consequently, the lack of sustainability of the Greek SIS to be a major factor of economic uncertainty. The system has acquired deep intra-generational inequalities caused by the discrimination in the years required for retirement eligibility and on the rules of pension cofinancing by the State Budget, which vary substantially among employees and different sectors of the economy. As various Governments sought to raise finances through taxation and increased current contributions, the system started acquiring inter-generational inequalities as well.

A factor that has concealed the inequalities from public attention and, thus, multiplied the current adversities was the fragmentation of the Greek SIS into many separate pension funds, each one having different rules, entitlements and financial opportunities depending on preferences of, and access to, the political system. The reason is that fragmentation facilitates the organization of privileged groups, which dominate public debates and influence political decisions to their own favor. In the past, the lobbies of the privileged groups have succeeded into thwarting major reforms and transferring the burden of adjustment to the taxpayer, thus perpetuating distortions and inequalities.

Entitlements of retirement age and minimum working period are frequently manipulated by Governments as a means to confer favors to various groups of 
political clientele, and are easily introduced by simple parliamentary approval without due consideration on the long-term sustainability. Similarly, the replacement ratio, i.e. the proportion of pension to working-time earnings, adjusted upwards in favor of certain groups, without any appeal to fairness among employees and retirees. Some sporadic reforms have been enacted in the past, though none of them radical enough to harness the tide of rising deficits or eliminate inequality. Tinios (2016) gives an extensive and informative account of reform attempts and failures during the postwar period, while a Symeonidis (2015) gives a concise description of the reforms enforced during 2010-2014.

Before the debt-crisis, Greece was having a high replacement ratio of around $100 \%$ across all earnings levels and allowed for generous early retirement schemes, as noted by OECD (2013, p. 42).

As aggregate pension expenditure was a key factor behind the collapse of the economy in 2010, the momentum of reforms on pensions vastly accelerated after the Greek debt-crisis. Most of austerity cuts and the organizational changes in the SIS was set as a pre-condition by the three bail-out Memorandum Agreements in 2010, 2011 and 2015. Cuts applied at a progressive scale on the level of pensions in order to reduce income inequality among pensioners; for a brief description see Matsaganis and Leventi (2016, Table P1). They included dropping the two extra annual installments (the so-called $13^{\text {th }}$ and $14^{\text {th }}$ pensions), imposing a solidarity tax and straightforward reductions of main pensions. All these measures led to fierce opposition by affected groups, and Governments, in a desperate hope to minimize their personal political cost, were reluctant to engage in a full and immediate implementation. This attitude perpetuated the problems, increased distortions and made a new series of changes unavoidable.

Although post-crisis reforms have reduced the replacement ratio below $80 \%$ and raised the retirement age from 58 to 65 years for the new pensioners, the accumulated inequalities continue to characterize the Greek SIS. For example, Symeonidis (2015) reports that although most pensions were cut after 2010, the income median of people above 60 years old fell less than the median of those below, thus the proportion of relative poverty was reduced. But since the number of actual working years was not taken into account in adjusting pensions downwards, unfairness against those with longer working-age and higher contributions continued. A further impediment is the chronicle lack of online digitalization of the system. This has made the task of accurately recording the 
financial details next to impossible, and prevented a thorough evaluation of costs incurred by the complicated rules and entitlements accrued to every specific category of pensioners.

A more ambitious reform was implemented in May 2016 (Law 4387), aiming at the unification of the Greek SIS and the centralization of pension calculation and allocation. A breakthrough is the restructuring of pensions into two components: on the one hand, the so-called 'national pension' not anymore related to contributions and wholly financed by the state budget; on the other the 'main pension' calculated on a wage average close to the date of retirement and taking into account the duration of contributions. Retirees with more than one pension claim will receive the national component only once, while others with paid contributions in excess of required thresholds are going to be awarded with slightly more generous replacement ratios. Kontiadis (2016) notes that merging the main SIS funds, combined with the unification of calculation rules and the establishment of a single collection mechanism for contributions, is in the right direction. However, the lack of managerial preparation has so far resulted in little progress in the field of institutional unification of the system.

Although the new system closes the income gap between pension holders, its overall impact on efficiency and fairness is very much in doubt. As it appears, the new system will tend to favor low-income single-pensioner versus higher-income earners or multiple claimants; for an analysis of distortions see Zambelis (2016). The second reason is that several categories of recent retirees managed to protect their own entitlements from the new rules, thanks to the establishment of a 'personal transfer' that compensates for the reduction envisaged by the new law. The normalization of recent and current entitlements is the subject of an agreement between the Greek Government and the European institutions, but not applied yet. Under the new framework, The younger workforce is, therefore, liable to higher contributions in order to finance the current SIS deficits and, nevertheless, will enjoy inferior retirement entitlements. This discrimination makes the Greek SIS to be actuarially unfair and creates counter-incentives for the younger generation to contribute to its financing.

Two phenomena make the legacy of incomplete and inefficient reform in Greece to look even more threatening today: the first is a systematic population ageing that made the expansion of pension entitlements in the past to be a lot more burdensome for public finances. The second is the deep recession followed the 
front-loaded implementation of the bailout programs since 2010. A series of economic and social adversities quickly appeared, exacerbating the problems of the Greek SIS accumulated thus far. To name but a few, activity collapsed by more than a quarter of pre-crisis levels causing a fall in incomes and the collection of insurance contributions. Furthermore, investment returns on social insurance funds shrunk after the collapse of sovereign bonds market and the partial debt default that took place in 2012. As a result, the SIS has entered a face of existential and multi-faceted crisis, the main aspects of which are described in subsequent sections.

Building on previous work by Christodoulakis (2011, 2016), the present article argues that reforming the SIS in Greece should look beyond just another round of fiscal correction measures, and suggests a set of rules and ideas capable to stop the process of disincentives and inequalities entrenched in the current system. The existing system should converge to the benchmark model through a combination of political initiatives, fiscal constraints and private incentives.

The rest of the paper is organized as follows: Section 2 describes some fundamental characteristics of the Greek SIS, including the fiscal burden and the adverse consequences of current recession and unemployment. Section 3 shows how adverse population dynamics are likely to further augment inter-generational inequalities, while Section 4 discusses the political and organizational problems that have hindered reform efforts in the past. Section 5 sketches the main idea of a new benchmark and suggests a road map how this can be implemented so as to overcome the reaction from vested interests. Section 6 summarizes the main conclusions.

\section{Unsustainable finances}

A key pathology of the system is demonstrated in Fig.1 that shows the average pension received by age group and the respective cohort of pensioners to total retirees. Despite the changes and fiscal cuts that took place in the recent past, it is evident that $27 \%$ of retirees to date continue to receive a pension before the age of 65. Even more disturbing is the fact that early retirees are entitled with the highest pensions: the average pension for those up to 65-year old amounts to Euros 964 per month and is $20 \%$ above the amount of Euros 800 received in average by the elder pensioners. 


\section{[Fig. 1, around here]}

The fiscal burden of a SIS is usually measured as the ratio of current public expenditure on pensions (PEP) to the country's GDP. Fig. 2 plots this ratio for Greece versus the average of 27 other member-states of today's European Union (EU). The European average is characterized by a steady - though mild - decline from mid 1990s until 2007. In the aftermath of the global financial crisis and the accompanying recession, the ratio peaked and then stabilized to a new level at around $12 \%$ of GDP.

Developments in Greece took a different course: despite solid GDP growth through the second half of the 1990s, the ratio was steadily on the rise due to an expansion of both pension entitlements and the number of retirees. A major initiative on reforming social security in 2001 was finally cancelled by massive opposition jointly organized by trade unions and pensioners. A less ambitious attempt to rationalize the Greek SIS by tightening retirement criteria and imposing restrictions on pension allowances finally implemented in 2002 and the burden subsequently stabilized at a level slightly above $11 \%$ of GDP.

[Fig. 2, here]

Soon, the burden started to rise again and continued unabated after 2005, though for different reasons before and after 2010. During the period 2005-2009, the number of pensioners as a share of total taxpayers increased from $27 \%$ to $28.5 \%$, while their income rose from $24 \%$ to $27 \%$ of total income, clearly suggesting a systematic generosity in setting pensions. ${ }^{2}$ The rate of growth in pensioners' income share slowed down only in 2010 after the first round of pension cuts was implemented by the bail-out requirements. Nevertheless, if PEP is expressed in GDP terms it seems to move even further away from the EU path due to the fact that the collapse of economic activity in Greece was far more pronounced than in other countries. Had Greece experienced a milder downturn in the aftermath of the global crisis, the public expenditure on pensions would have stayed around

\footnotetext{
${ }^{2}$ Calculations are based on data from General Secretary of Information System. http://www.gsis.gr/gsis/info/gsis_site/PublicIssue/Statistics.html
} 
$13 \%$ of GDP, considerably lower than the present level, though still in excess of the EU27 mean.

\section{[Fig. 3, here]}

To demonstrate the effect of recession in exacerbating its trend, PEP is juxtaposed with the rate of unemployment. Fig. 3 displays a strong and positive correlation that is triggered by the combination of recession and over-taxation through the following channels:

(a) Higher unemployment is associated with lower activity, thus directly reducing the denominator of PEP to GDP ratio.

(b) A rise in unemployment reduces contributions, thus SIS deficits widen, raising the requirements of public financing.

(c) Insurance contributions went further down due to increased moonlight activity in order to enhance take-home wages by avoiding taxation. Employers were just as keen to hire unregistered labour in their attempt to conceal taxable income and evade their own SIS contributions.

(d) The repatriation of economic immigrants to their country of origin and a massive emigration of young Greek professionals abroad in search of jobs. Even if employment opportunities emerge again in the future, the usual hysteresis in rejoining the labour market is bound to exert a serious reduction in future contributions to the Greek SIS for many years.

(e) In view of raising the retirement age, several thousands of employees chose early retirement schemes to avoid staying at work for longer than envisaged by previous entitlements. This reduced insurance contributions and drove public expenditure to even higher levels. Fig. 4 shows that during the crisis period 2009-2013, new retirements almost doubled in the public sector and among professionals in comparison to the pre-crisis rates. In contrast, new retirements among private sector employees remained below the rate they had in 2004, since they lacked similar entitlements.

\section{[Fig. 4, here]}

\section{Unsupportive demographics}

Another source of mounting pressure on the Greek SIS comes from the systematic ageing of population and the decline of the working age cohorts, as described below. 


\subsection{Population ageing}

Fig. 5 shows developments in Greece as compared to other European countries. In 2000 , the share of people over- 65 constituted $16.6 \%$ of total and seemed to approach a steady state of around 19\% in 2009. In the aftermath of the crisis, the share surged by another percentage unit due to the emigration of younger cohorts abroad.

\section{[Fig. 5, here]}

The change in population deciles before and after the crisis is shown in Fig. 6. In 2011, all age cohorts up to 79 year old appear to decline relative to 2007. The fall is more pronounced for the ages between 20-39 year old, where most of those seeking employment abroad are likely to come from. It is noticeable that the only cohort with an increase between 2007 and 2011 is the over-80s, so that pressures on the welfare and medicare systems are expected to rise.

\section{[Fig. 6, here]}

\subsection{The decline in working-age population}

Because of systematic ageing, the proportion of working-age population in Greece has constantly declined since the beginning of the $21^{\text {st }}$ century before further accelerating due to the emigration abroad. For comparison, Fig. 7 shows that the European average also deteriorated after the global crisis, albeit moderately, while working-age population in neighboring Turkey was rising fast.

[Fig. 7, here]

\subsection{Generational inequalities}

The above developments imply that the financial requirements posed by current and soon-to-be pensioners are on the rise, while the reservoir of active labour force and the concomitant contributions are shrinking. Though it constitutes a time-bomb of inter-generational conflict, it is very difficult to be disarmed because change is blocked by the vested interests built upon intra-generational inequalities. On the eve of a reform that envisages a rise in retirement age, a reduction of the pension to salary ratio or even a modest restriction to preferential 
entitlements, the affected groups react decisively and often successfully in annulling the reform.

This is a typical case of status-quo winning against the interests of those outside the system of privileges, even when the latter are a majority but lack coordination. The status-quo alliance includes the groups of privileged pensioners and employees in the banking sector, public utility companies and the upper-class of professionals (mainly engineers, lawyers and doctors). It is supported too by the political personnel and other smaller groups, which enjoy pension rights that are disproportionately high relative to their contributions.

Inter-generational inequality got even worse, when a firm distinction between those insured before and after 1993 was established. The latter had since to pay higher contributions and need to complete a longer working period before retiring.

Unless major downward adjustments are put in place, the present generation of employees will be charged with even higher contributions to support current pensions at levels that are inconceivable to be enjoyed by themselves when they reach retirement age. A rise in social insurance contributions or in the income tax rate of those currently employed has an adverse effect on employment through the so-called 'tax wedge' effect. ${ }^{3}$ In a study for the OECD economies, Bassanini and Duval (2007) used data over the period 1982-2003 and established that a 10\% rise in the tax wedge causes an increase in unemployment rate between $2.2 \%$ and $2.8 \%$ of the labour force. In turn, this will further deteriorate PEP as implied by Fig. 3.

\section{The Impediments to Reform}

Another factor that impedes a thorough reform plan in social insurance is that the political system is usually unprepared to face a prolonged protest by privileged groups and the impetus for change soon evaporates. Short-termism is deeply rooted in Greek politics through all the postwar period, no matter what the type of Government being in office. The fear of adverse political repercussions that a long reaching restructuring of the pension system could have had on the then ruling party forestalled several reform initiatives in the past. Tinios (2016) describes how major pension reforms were put aside by Conservative

\footnotetext{
${ }^{3}$ The tax wedge is defined as the sum social insurance contributions and income tax as percent of nominal wages and its rise cuts take-home wages and pushes for higher nominal wages, finally increasing labour costs and reducing employment.
} 
governments in 1958, 1978 and 2008 or by Centre-Left governments in 1965, 1998 and 2001. Even in the absence of parliamentary democracy, the military junta was shaken enough by protestations and cancelled a pension bill in 1968 .

In practice, indecisiveness is encouraged by the occurrence of frequent elections and the pre-election tactics that prevail. Going to the polls, ministers tend to be reluctant in long term planning and implementation of reforms since they may not be in office to reap any positive outcome. The extremely short tenure for Social Insurance ministers is depicted in Fig. 8, showing that since 1974 duration was in average no more than fifteen months: Seventeen out of a total of 34 ministers served for less than a year, while more than a quarter of them served for less than six months.

\section{[Fig. 8, here]}

Nevertheless, there might have been additional counter-incentives, due to the unequal distribution of pensions across the country. The average pension paid in rural areas is considerably below the national average due, obviously, to the larger proportion of farmers receiving the small 'agricultural pension'. The highest average pension income occurs in the wider area of Athens, where the majority of retirees from banking sector, public utilities and public administration are living. Yet, fourteen out of seventeen Labour ministers ${ }^{4}$ served between 1995-2015 were selected among MPs from the populous districts of wider Athens, thus making the effort of achieving a more equitable distribution of pensions to look selfdefeating. The reason is that a rationalization of the pension system should obviously include a curtailment of the most privileged constituencies, thus a minister elected in Athens would be paying a high price in terms of personal political prospects. Given the clientilistic character of electoral ties in Greece and the vast networking of pensioners' unions, is no wonder that the period in office was so abruptly terminated and the reform effort abandoned.

Finally, the lack of political incentives to implement a pension reform is intertwined with the difficulty of a precise description of the system, both fiscally and structurally. A detailed accounting of the Greek SIS is next to impossible,

\footnotetext{
${ }^{4}$ Until 1994, the portfolio of Social Insurance was part of the Ministry of Health and then transferred to the Ministry of Labour. The move was seen as an attempt to make SIS provisions more compatible with labour market characteristics.
} 
due to the sheer multitude of social insurance organizations, the complexity of the entitlement provisions, and the lack of a full-scale digitalization of the payment system. Even in the absence of political short-termism, the design of reforms would have been undermined by the system indeterminism as important information on actual financial flows may not be available or predictable on a detailed and well-documented basis.

All the above factors explain why past reform efforts of the Greek SIS mostly constituted piecemeal corrections, which - at best - offered some short-term relief without terminating the main factors of $\mathrm{p}$ fiscal deficits and increasing inequalities.

\section{A New Benchmark}

Given the inequalities and lack of sustainability discussed in the previous Sections, reforming the social security system in Greece is reasonably expected to have an extensive effect on both the economy and society in terms of efficiency, equity and equality before the law. Feldstein (2005) suggests that for a social reform to be politically feasible it should be based on program transparency and enhance individual choice, thus a careful choice of policy indicators and transition rules are required first as explained below.

\subsection{A closed PAYG system}

Taking into account the strong reactions that led to repeated failures in the past, Greece should find a realistic way to reform the SIS, without having to retort to the extremes of a a "fully-funded" system. Such a type of reform precludes social redistribution and is exclusively based on the future market return of individual contributions. The attempt to introduce such a model in Greece will give rise to such a vehement resistance by insiders that all efforts to establish it will be frustrated.

A realistic compromise between the uncertainty of the open "Pay-As-You-Go" system and the straightjackets of the "fully-funded" system would be a closed PAYG system, similar to that applied in Italy or Sweden; for a comprehensive review see Holzmann and Palmer (2006). Such a system functions by adopting explicitly defined parameters concerning the co-financing of personal contributions through state participation. 
The main issues in a SIS concern the proportion of pension finance that is covered by own-contributions and whether the rules apply equitably among the various categories of pensioners and between generations. A simple way to portray these relationships is to compare the present value of an individual pension at the point of retirement with the present value of own-contributions during work-life. If the two sides match, the system is "fully-funded"; otherwise additional finance should come from current generation employees in the form of contributions and/or taxes. In general, we have:

$$
\frac{F P V\{\text { pensions }\}}{B P V\{\text { contributions }\}}=1+k
$$

In the above expression, function FPV \{.\} denotes the forward present value calculation of pensions expected to be handed over the retirement years, while $B P V\{$.$\} is the backward present value calculation of SIS contributions that have$ been paid during the past working years.

Parameter $(k)$ denotes the extent to which the value of pensions surpasses owncontributions. A "fully-funded" system corresponds to $k=0$, while $k>0$ implies that pensions should be supported by a PAYG system or by the State Budget. A system is intra-generationally fair if parameter $(k)$ is the same across various sectors of current employees. To be inter-generationally fair it must retain the same non-negative value along current and future pensioners.

The economic assessment of pension systems formally takes place by employing actuarial calculations for each pension fund, so that all parameters are properly taken into account. However, quite often such an analysis gets so complex that a policy debate is difficult to be organized as alternative options are not technically perceptible by the wider public. This makes the public reaction to pension reforms to be manipulated by outside political impressions and leads many citizens to resist changes even if they might be eventually beneficial for them. More often than not, the actuarial complexity is exploited by the most organized vested interests in order to oppose reforms in the first place and, thus, perpetuate their own privileges.

For the consequences of a reform to be properly communicated to the interested parties, two conditions should be ensured: one is a system of personal actuarial accounting so that each citizen can assess the impact of reforms on his/her own 
pension profile. The other is that the policy debate should focus around only a few and well-understood indicators that are crucial for the operation and sustainability of the entire SIS. Below is a brief description of these reform requirements.

\subsection{Individual Actuarial Accounts}

The impact of the reform should be assessed on a personal level so that each citizen can easily choose between alternatives. This can be done through the introduction of a pension and insurance contributions account for each person insured. The form is similar to a bank account and systematically records the insurance contributions paid by the worker, as well as those paid by the state and the employer.

The account is capitalized in regular intervals and the employees are informed about the insurance credit accumulated in every period. Given a degree $(k)$ of pension co-financing, the individual actuarial calculation gives them the option to select from a combination of retirement age and pensions that are compatible with their accumulated savings, as implied by (1). In case employees are hired by an entity using different co-financing parameters $(k)$, the pension capital and returns adjust accordingly. Besides, this helps labour mobility among various sectors without any loss of insurance contributions, since all pension returns from each insurance period are added up and no contribution is waisted.

\subsection{Parsimonious policy indicators}

The key policy choice regards the co-financing parameter $(k)$. The proportion of co-financing should take into account the peculiarities of each trade specialization, but otherwise the replacement ratio and the time-profile of worklife and retirement apply universally to all. A description of the architecture of such a system with universal rules has been initially described in detail by Christodoulakis (2011). A similar proposal was more recently prepared by an expert committee set up by the Government in 2015, as reported by Nektarios (2016). A synthesis of the two approaches can be found in Christodoulakis, Nektarios and Theocharis (2018).

A representative indicator of actuarial fairness should explicitly take into account both the actual duration of contribution payments, as well as the expected period of receiving a pension. The Period-Enhanced Replacement Ratio (PERR) is defined as follows: 


$$
\text { PERR }=\frac{[\text { Pension }]}{[\text { Average Wage }]} \cdot \frac{[\text { Pension years }]}{[\text { Years of contributions }]}
$$

The first fractional term in the right-hand-side is the usual replacement ratio, while the second gives the proportion between pension time and work time. In the Appendix, it is shown that, under some simplifying assumptions, the above fractional terms are the main determinants of expression (1). Hence, reforming the rules regarding the two ratios is an effective approximation of simultaneously improving fairness and sustainability in the Greek SIS.

To make index PERR more egalitarian, policy measures should aim to adjust not only the traditional replacement ratio but also the duration of pension entitlements relative to that of contribution payments in the following sequence: First, a unified national benchmark for PERR will support a fiscally sustainable social insurance system. Then, the target can be reached through various policy combinations of the two ratios as in (2). Alternative options are possible concerning particular pension funds as a whole or each pensioner individually. For example, categories with a high period ratio should be awarded with a lower replacement ratio, or else face an increase in contributions or a rise in retirement age.

The optimal combination should be carefully examined before a universal implementation is enforced. For example, it is frequently argued that, no matter how distortive an early retirement is in actuarial terms, it nevertheless releases work posts and thus contributes to new employment opportunities. In practice, however, there is no convincing evidence of such effects: Barr and Diamond (2008) notice that evidence from several countries shows that no pattern exists of lowering unemployment by applying early retirement schemes. The effect is probably even more distortive in Greece, where part of early retirees are engaged in informal employment afterwards, cutting opportunities from other candidates and avoiding contributions. On the other hand, cutting pension entitlements for early retirees is likely to exert a downward pressure on aggregate demand and depress new employment. On balance, raising the time threshold is more likely to help activity and new job creation rather than impede them and, thus, should be preferred to pension cuts.

\subsection{Implementation and transition rules}

The operational unification of existing funds envisaged in Law 4367/2016 should proceed along a carefully drafted road map towards unified rules, without 
any loss in present-value equivalent entitlements. In this case, the term "entitlement" denotes the accrued part of preferential arrangements. The portion of the entitlement that is preserved is easily calculated as the ratio of the years of employment up to that point to the total time remaining for the preferential arrangement to take full effect.

Suppose, for example, a person who expects to receive a full pension after 25 years of work and has already worked for 15 years. When moved to the unified fund with the provision of working for 35 years, this person will hold a fraction of $15 / 25$ or $60 \%$ of the pension entitled to thus far. This amount is supplemented by $20 / 35$ of the new pension, in accordance with the subsequently uniform rules, if this person completes 35 years of work. If, however, the person wishes to retire after just 25 years of work, as initially entitled to, then the additional amount will be equal to $10 / 35$ or just $28 \%$ of the new pension. In this case, the total pension will amount to $88 \%$ of the initial arrangement.

\section{Conclusions}

Two major conclusions emerge from the above analysis: First that short-term corrections are unlikely to face the deep structural deficiencies of the system and a major overhaul is deemed necessary. Although public expenditure for pensions was reduced in 2011 and again in 2012 and 2016 in absolute terms, this is not enough to make the system sustainable in the long run. In fact, the policy is to some extent self-defeating, in the sense that pension cuts (and especially on the lower ones) led to a serious decline in aggregate demand and caused a fall in output, thus further exacerbating the public finance ratio.

Second, that population dynamics are bound to make the fiscal burden even worse in the near future. With the present generation of employees burdened by higher contributions to support pensioners, the incentives to stay and work in Greece are diminishing as witnessed by the current surge of outward emigration, thus further shrinking the basis for financing the rising population of pensioners.

A key reform is restructure the Greek SIS as a universal system, based on the premises of the recent Pension Reform Act of Law 4367/2016. The political and financial advantages from the creation of a universal insurance fund are evident and extensive, including:

a) uninterrupted labour mobility; 
b) full transparency and disclosure of egregious pension inequalities;

c) easy calculation of the fiscal cost corresponding to each category;

d) freedom to choose retirement age;

e) equity, partial for today's citizens and full for the future generations.

But, no matter how well-intentioned it may be, reforming the Greek SIS is not likely to be successful if implemented without paying due attention to the overall macroeconomic environment. The fiscal burden of SIS moved in line with unemployment, while the incentives for increasing participation in the labour force are more likely to operate if activity is on the rise and new investment is attracted. All these requirements point to the direction of avoiding any further burdening of contributions from current and future generation of employees and employers; in fact, relieving the existing costs is essential for setting off investment activity. A full-scale proposal is described in the study by Christodoulakis, Nektarios and Theocharis (2018).

The essence of the new changes is that the burden falls unequally on between and within generations. For it must be borne mainly by the current population of pensioners or those close to retirement, not by the younger generations of employees as the convenient option has been in the past. Within the elder generation, the burden must be allocated mainly to the groups of pensioners mostly privileged in retirement entitlements in the past. At the same time, the welfare system provides protection from poverty and social marginalization of the elderly poor with inadequate pension entitlements. 


\section{References}

Barr N. and P. Diamond, 2006. The economics of pensions. Oxford Review of Economic Policy, 22 (1), pp. 15-39 DOI: 10.1093/oxrep/grj002

Bassanini A. and R. Duval, 2007. "The Determinants of Unemployment across OECD Countries: Reassessing The Role of Policies and Institutions". OECD Economic Studies, Vol. 2006/1.

Campanella E., 2016. "Europe's Generation Gap: How Pensioners Are Threatening the Continent's Future". Foreign Affairs, July.

Christodoulakis N., 2011. Can the Titanic be rescued? From Memorandum, back to Growth, 2011, Polis editions. Athens.

Christodoulakis N., 2016. "Radical Redesign of Rules, Not Piecemeal Interventions". EDKA, Review of Social Insurance Law, vol. 651, 1, pp 28-36.

Christodoulakis N., M. Nektarios and H. Theocharis, (2018). Restarting the Greek Economy: How lowering primary surpluses, taxes and social insurance contributions can lead to higher growth, employment and a more sustainable public debt. Report published by Dianeosis Group, Athens, February.

Feldstein, M. S. (2005), 'Rethinking Social Insurance', American Economic Review, 95(1), pp 1-24.

Holzmann R. and E. Palmer, (Editors), 2006. Pension Reform Issues and Prospects for Non-Financial Defined Contribution (NDC) Schemes. The World Bank, Washington, D.C.

KEPE, 2014. Administrative reform and operational modernization of social insurance structures. KEPE publications. June. Athens.

Kontiadis X., 2016. "A Critical Assessment of the Insurance Reform Draft". EDKA, Review of Social Insurance Law, vol. 651, 1, pp 72-74. Athens.

Matsaganis M. and Ch. Leventi, 2016. "The returns of pensions in theory and practice”. EDKA, Review of Social Insurance Law, vol. 651, 1, pp 75-90.

Athens.

Nektarios M., 2016. "An Alternative Proposal for the Social Insurance Issue: A new system of pensions for the new generations". EDKA, Review of Social Insurance Law, vol. 651, 1, pp 63-71. Athens. 
OECD, 2013. Pensions at a Glance: OECD and G20 Indicators. Paris.

Samuelson P. A., 1954. 'An Exact Consumption-Loan Model of Interest with or without the Social Contrivance of Money.' Journal of Political Economy, 66(6), pp 467-482.

Georgios Symeonidis (2015). "The Greek Pension Reform Strategy 20102014: A leap forward". Hellenic Actuarial Authority, Discussion paper, March.

Tinios P., 2016. "The predetermined failure of the Social Security Reform: Target ignorance, self-trapping, inability of radical change". EDKA, Review of Social Insurance Law, vol. 651, 1, pp 16-27. Athens.

Zambelis P., 2016. "Why the new insurance Law 4387/2016 does not offer a solution to the social insurance system'. EDKA, Review of Social Insurance Law, vol. 652, 2, pp 207-211. Athens. 


\section{Appendix}

\section{Deriving the period-enhanced replacement ratio}

Calculations are presented in continuous-time for analytical simplicity. Discretetime expressions are available by the author. The following definitions are adopted: $P$ denotes the pension, $W$ the nominal wage, $q$ the rate of social insurance contributions, $r_{W}$ and $r_{R}$ the rates of return during working life and retirement respectively, $T_{W}$ and $T_{R}$ the age of entering work and retirement respectively, and $L$ the life expectancy.

Function $F P V\{$.$\} denotes the forward present value calculation of pensions that$ are expected to be received for the next $\left(L-T_{R}\right)$ retirement years, while BPV\{.\} the backward present value calculation of SIS contributions that have been paid during the past $\left(T_{R}-T_{W}\right)$ working years.

Retirement is assumed to take place at period $\mathrm{t}=0$ and the retiree expects that at time $\mathrm{t}>0$ he/she is going to receive a pension equal to $\left\{P_{0, t}^{e}\right\}$ for the next $\left(L-T_{R}\right)$ periods. With a rate of return on capital equal to $\left(r_{R}\right)$ the cost of pensions in present value terms is given by:

$$
F P V\left\{P, r_{R},\left(L-T_{R}\right)\right\}=\int_{0}^{L-T_{R}} \exp \left[-r_{R} t\right] \cdot P_{0, t}^{e} \cdot d t
$$

The retiree has entered employment at the age $\left(T_{W}\right)$ and in period $(s)$ of working life he/she received a wage $\left(W_{S}\right)$ and paid social insurance contributions at a rate $\left(q_{S}\right)$. With a rate of return on insurance savings equal to $\left(r_{W}\right)$ the present value of accumulated contributions is given by:

$$
B P V\left\{q W, r_{w},\left(T_{R}-T_{W}\right)\right\}=\int_{-\left(T_{R}-T_{W}\right)}^{0} \exp \left[+r_{W} s\right] \cdot q_{s} W_{s} d s
$$

To obtain more easily handled expressions a number of simplifying assumptions are made as follows:

A1.Pensions, wages and contributions rate are kept constant over time.

A2.Working period was uninterrupted by unemployment.

A3.The rates of return on capital are equal and constant over time, i.e. $r=r_{W}=r_{R}$. 
Under the above assumptions ( $3 \mathrm{a}$ ) and (4a) can be explicitly calculated as:

$$
\begin{aligned}
& F P V\left\{P, r_{R},\left(L-T_{R}\right)\right\}=\frac{1}{r} \cdot\left[1-\exp \left(-r\left(L-T_{R}\right)\right)\right] \cdot P \\
& \operatorname{BPV}\left\{q W, r_{w},\left(T_{R}-T_{W}\right)\right\}=\frac{1}{r} \cdot\left[\exp \left(+r\left(T_{R}-T_{W}\right)\right)-1\right] \cdot q \cdot W
\end{aligned}
$$

For relatively small values of $r\left(L-T_{R}\right)$ and $r\left(T_{R}-T_{W}\right)$ the Taylor approximation for the numerators in the right-hand-side of expressions $(3 \mathrm{~b}, 4 \mathrm{~b})$ gives:

$$
\begin{aligned}
& 1-\exp \left[-r\left(L-T_{R}\right)\right] \approx r\left(L-T_{R}\right) \\
& \exp \left[+r\left(T_{R}-T_{W}\right)\right]-1 \approx r\left(T_{R}-T_{W}\right)
\end{aligned}
$$

Recalling definitions (3a) and (4a), using approximations (5a, 6a) and dividing (3b) and (4b) by parts, actuarial expression (1) becomes:

$$
\frac{F P V\{\text { pensions }\}}{B P V\{\text { contributions }\}}=\frac{P}{q W} \cdot \frac{\left(L-T_{R}\right)}{\left(T_{R}-T_{W}\right)}
$$

The period-enhanced replacement ratio is given by

$$
1+k \approx \frac{P}{q W} \cdot \frac{\left(L-T_{R}\right)}{\left(T_{R}-T_{W}\right)}=\frac{1}{q} \cdot P E R R
$$

The above approximation is the basis on which the policy analysis in Section 4 is conducted. For more significant values $r\left(L-T_{R}\right)$ and $r\left(T_{R}-T_{W}\right)$ the Taylor approximation should include higher-order terms, but nevertheless the relationship holds in the same direction. 


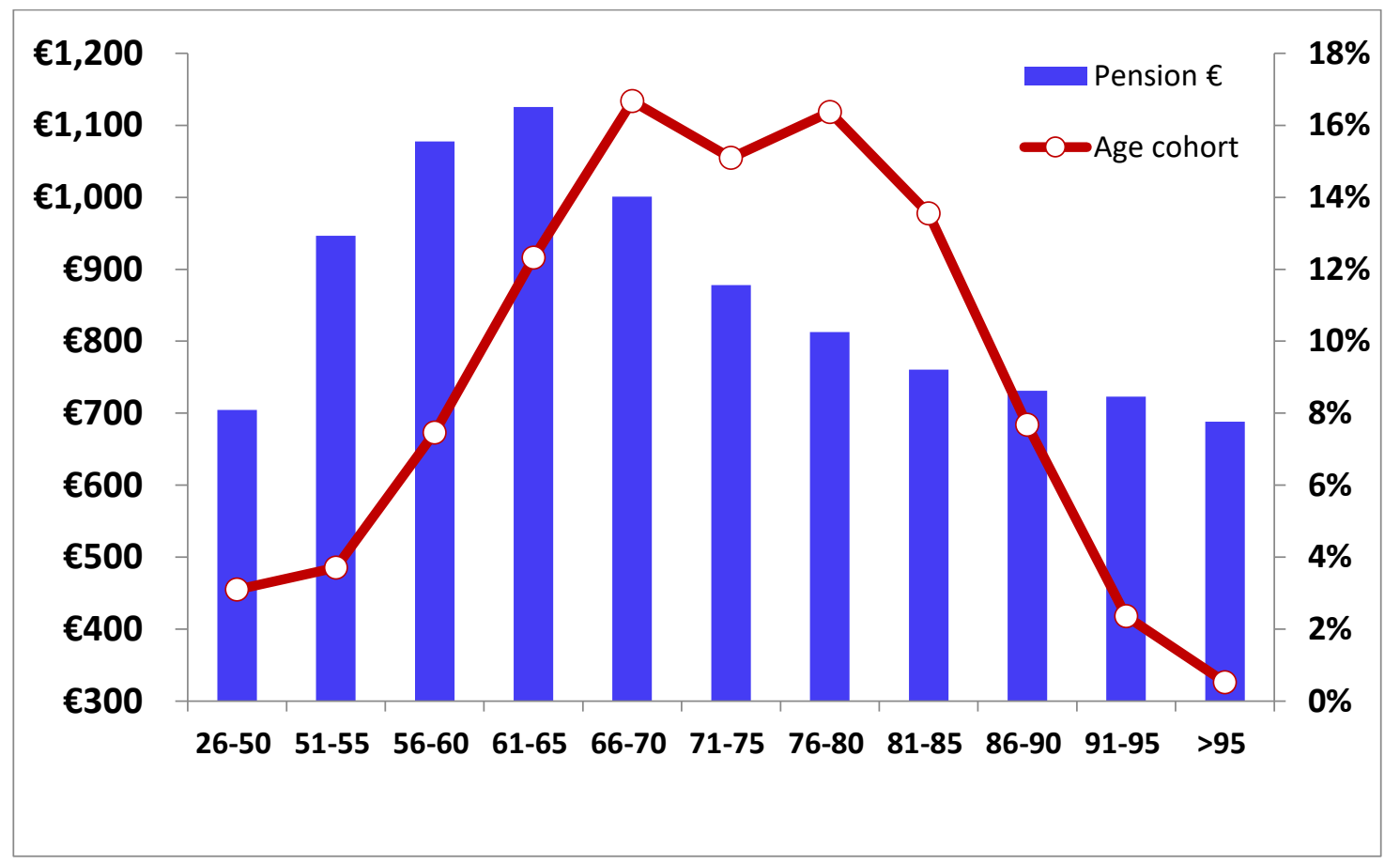

Fig. 1. Pensions by age group, monthly average July 2015.

Notes: The Lhs shows average monthly pensions in Euros as per July 2015, and the Rhs the age cohort in \% of total pensioners. A cohort below 25 years is omitted as this includes only pension heirs, not pensioners. Source: HDIKA, Monthly Record of Pension Payments and Social Transfers. Report No. 26, July. Table 4, p. 6, July 2015. Unified System of Pension Auditing and Payments "Elios'. 


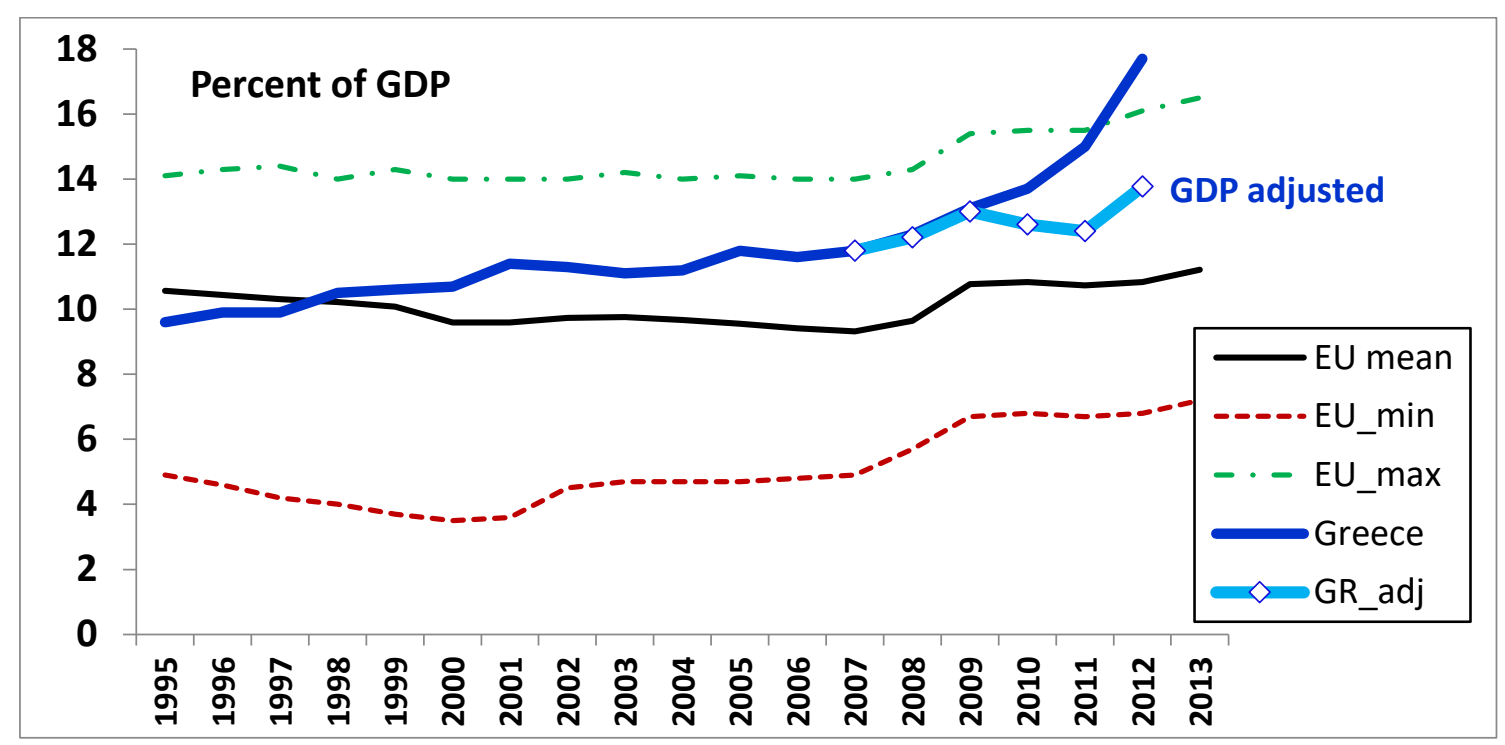

Fig. 2 Public expenditure on pensions as percent of GDP

Notes: The low and high contours represent the minimum and maximum levels prevailing each period in EU27. Source: Pension data from OECD Factbook 2014, PORDATA. Growth rates calculated from AMECO database. 


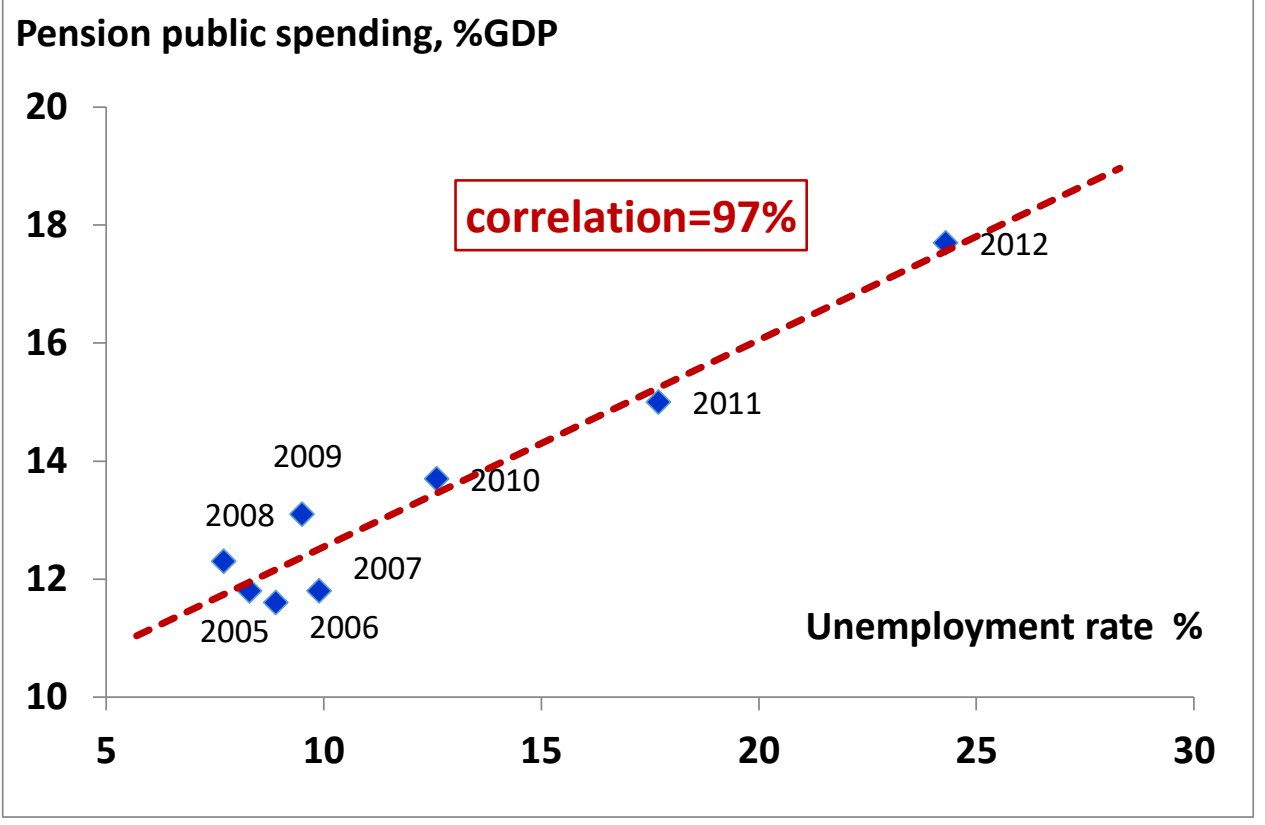

Fig. 3. Public expenditure on pensions as percent of GDP and unemployment rate in Greece 2005-2012.

Source: Pension data from OECD Factbook 2014, PORDATA. Unemployment data from AMECO Database. 


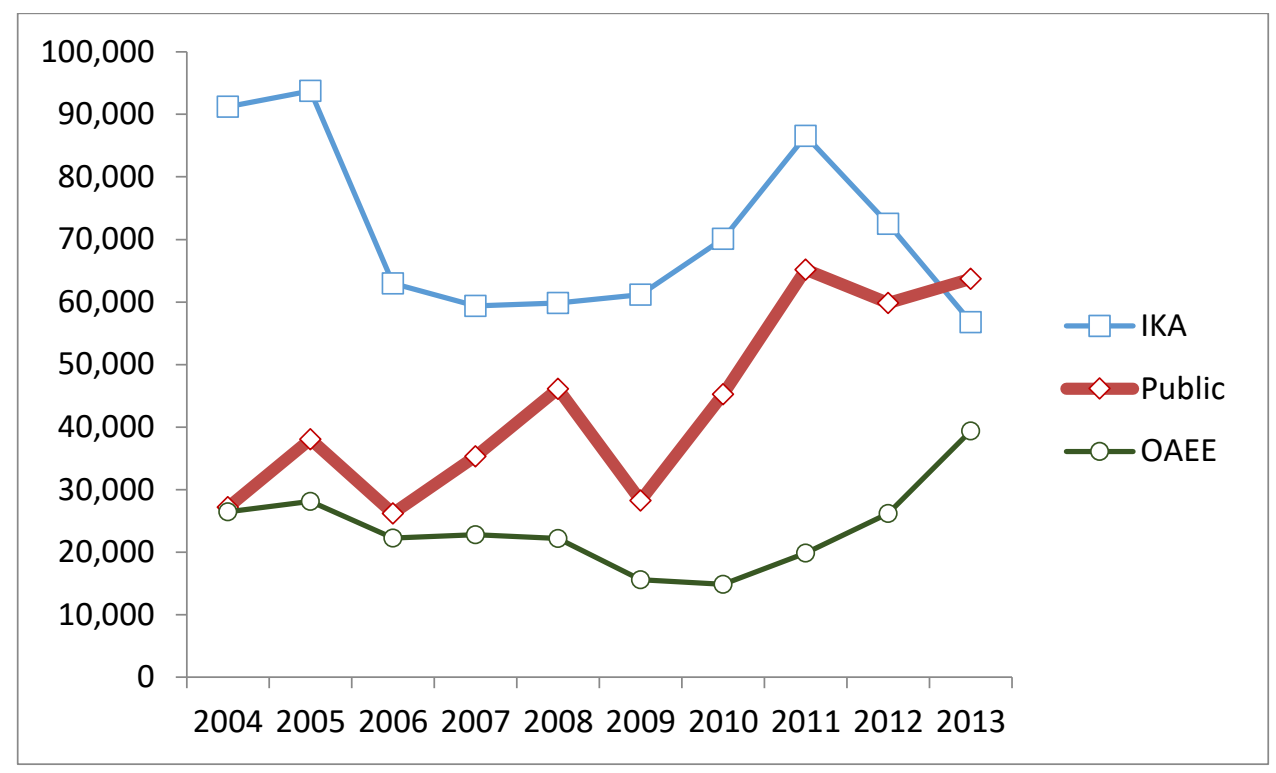

Fig. 4. New retirements $2004-2013$ by sector

Notes: IKA includes private sector employees; OAEE professionals and SMEs. Source: KEPE (2014, Table I.4). 


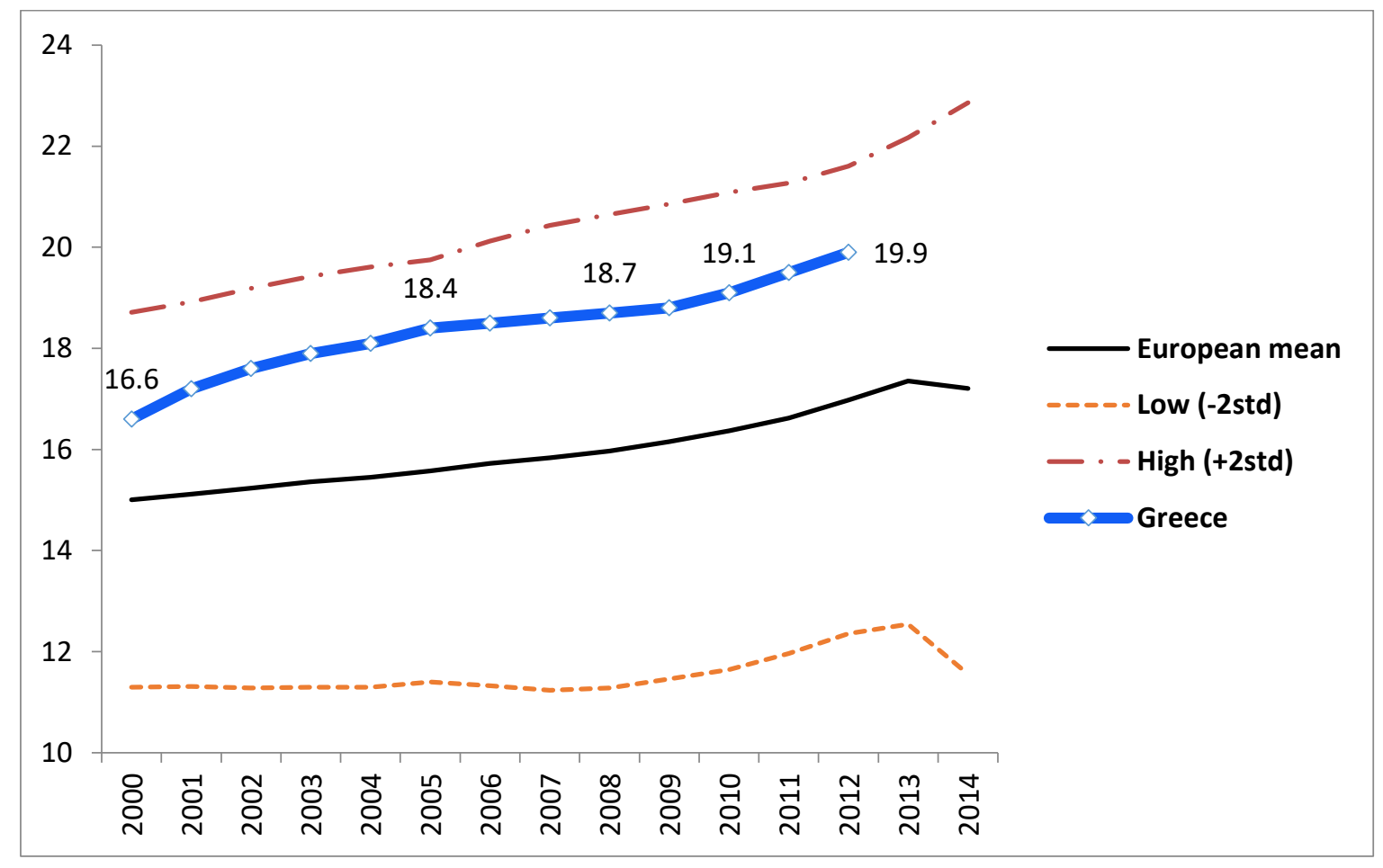

Fig. 5. Population share of age 65 and over in Greece and the EU

The European reference includes 19 EU countries plus Iceland and Norway, excluding Greece. The mean obtained as simple average. The low and high contours are two standard deviations below and above the mean.

Source: Data from OECD Factbook 2014, compiled by thee author. 


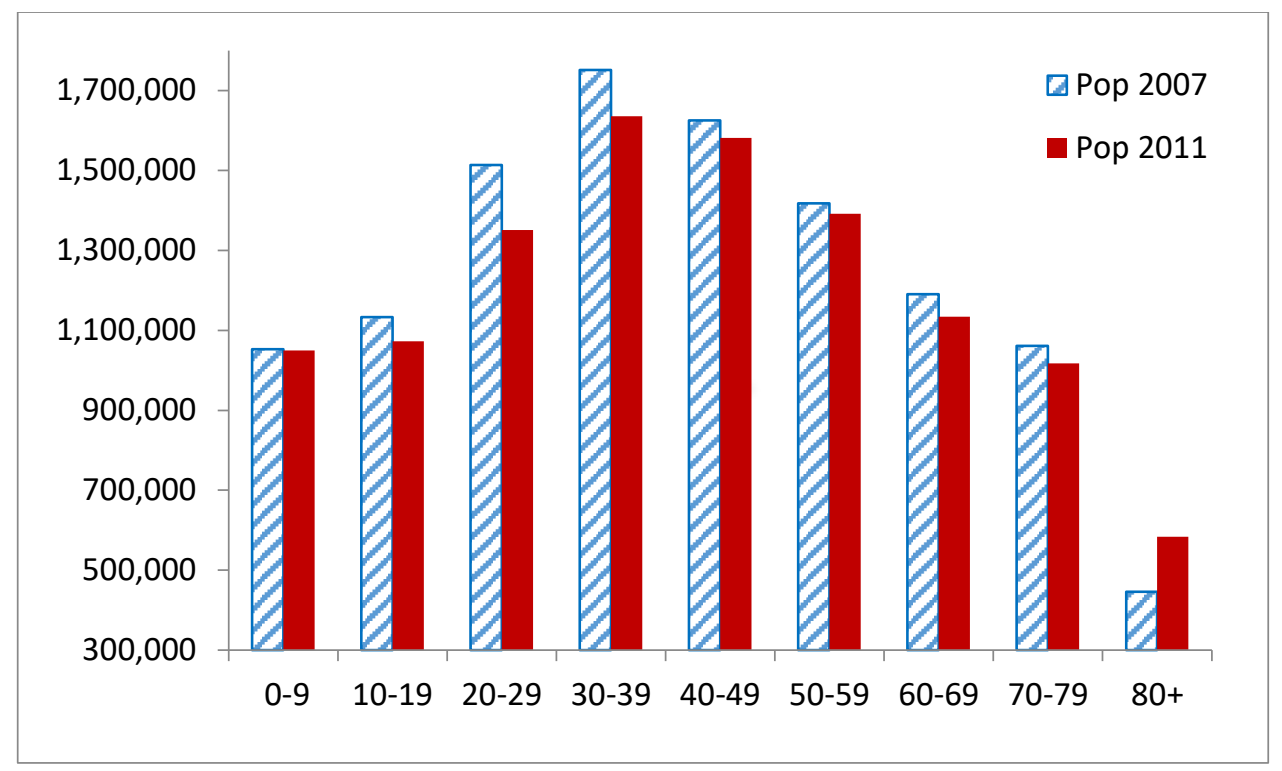

Fig. 6. Population in Greece by age groups.

Source: Census 2011. Table 2A. ELSTAT publication.

Data for 2007: Concise Statistical Yearbook, ELSTAT, Table II.5. http://dlib.statistics.gr/Book/GRESYE_01_0003_00040.pdf 


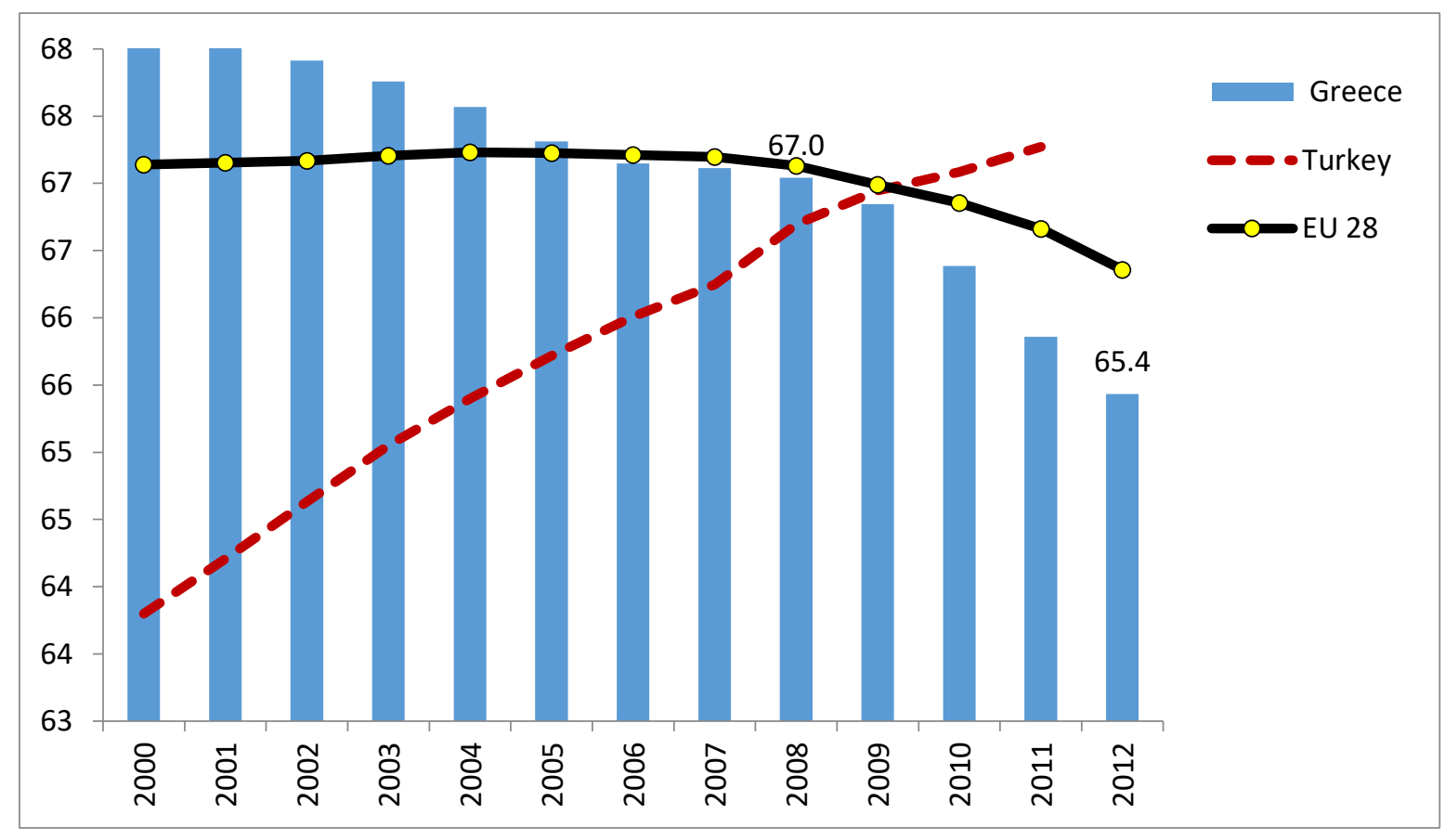

Fig. 7. Working-age population 2000-2012

Source: OECD Factbook 2014: Economic, Environmental and Social Statistics 
Social Insurance ministers' tenure 1974-2015, months

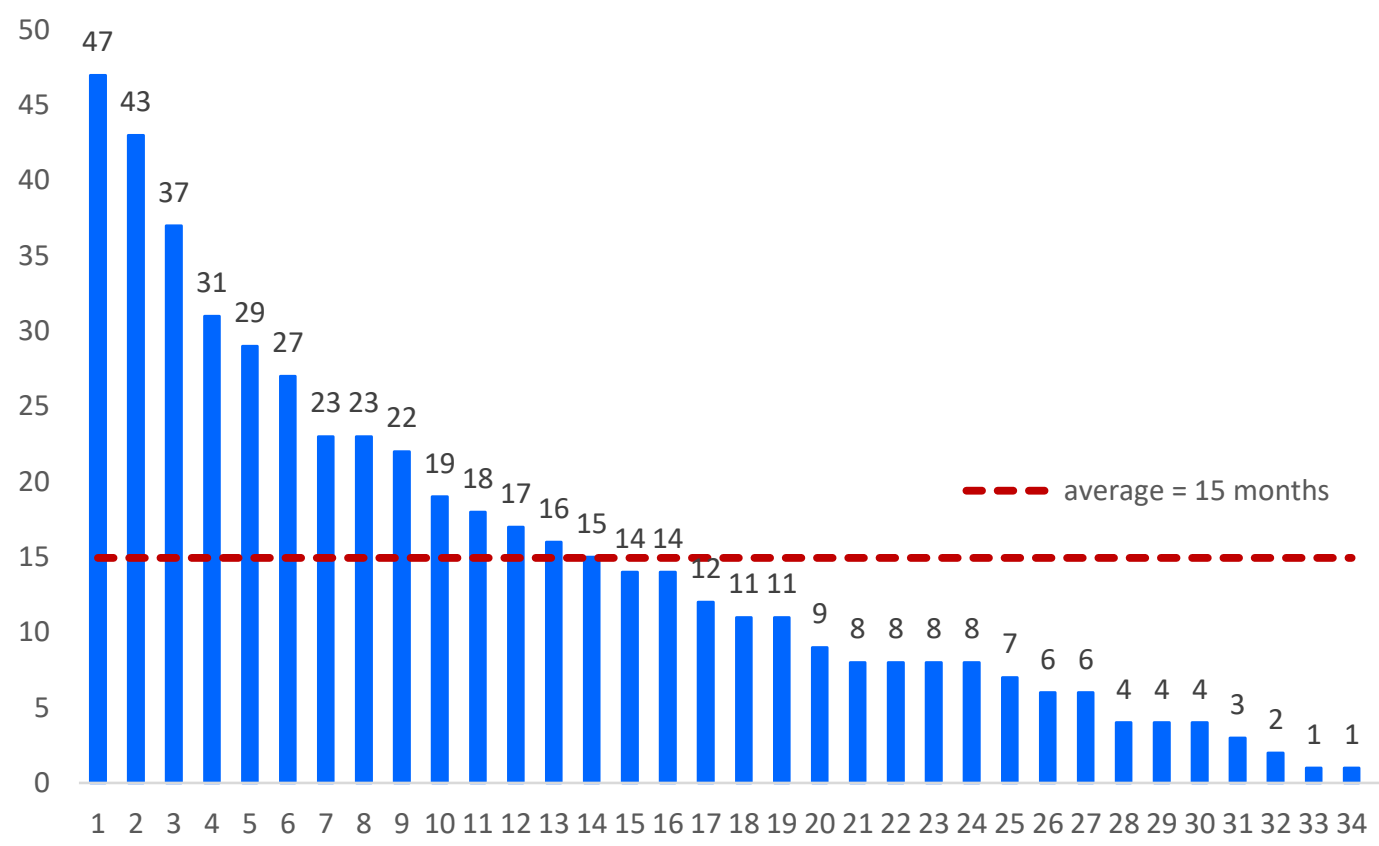

Fig. 8. Social Insurance ministers' tenure in office 1975-2015. Note: Until 1994, Social Insurance was part of the Ministry of Health, then removed to the Ministry of Labour. Duration in months. Author's calculations.

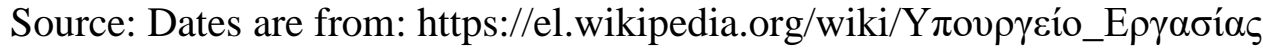

